\title{
DIÁLOGOS INTERCULTURAIS ESCOLA/COMUNIDADE E SUAS REPERCUSSÓES NO PROCESSO DE ALFABETIZAÇÃO DAS CRIANÇAS DAS CLASSES POPULARES
}

\author{
Mairce da Silva Araújo* \\ Nádia Cristina de Lima Rodrigues**
}

\section{Resumo}

Este trabalho é um recorte da pesquisa que foi desenvolvida no Mestrado em Educação da FFP/UERJ em uma escola pública, localizada na área rural do município de Cachoeiras de Macacu, no interior do estado do Rio de Janeiro, que atende a uma comunidade tradicional formada há pelo menos 200 anos. Neste trabalho, trazemos a reflexão sobre até que ponto a perspectiva monocultural, fazendo-se presente na escola, pode rotular e estereotipar diferenças culturais, constituindo um empecilho à educação popular. Tendo como principais interlocutores teóricos Sarmento, Larrosa, Gusmão e Freire a partir de uma metodologia de pesquisa de cunho participativo, buscamos compreender como se dá esse processo, bem como encontrar pistas para a produção de um diálogo intercultural na escola que contribua para a revalorização das vozes, dos conhecimentos, das práticas sociais das populaçóes historicamente excluídas da escola.

Palavras-chave: Cultura. Educação popular. Diálogo intercultural.

\section{INTRODUÇÃO: UM PONTO DE PARTIDA PARA A DISCUSSÁO}

\author{
Os ninguéns \\ As pulgas sonham com comprar um cão, \\ e os ninguéns com deixar a pobreza, \\ que em algum dia mágico \\ a sorte chova de repente, \\ que chova a boa sorte a cântaros; \\ mas a boa sorte náo chove \\ ontem, nem hoje, nem amanhã, nem nunca, \\ nem uma chuvinha cai do céu da boa sorte, \\ por mais que os ninguéns a chamem \\ e mesmo que a mão esquerda coce, \\ ou se levantem com o pé direito, \\ ou comecem o ano mudando de vassoura. \\ Os ninguéns: os filhos de ninguém, os donos de nada.
}

Professora Dr. ${ }^{a}$ Associada da Faculdade de Formação de Professores, da Universidade do Estado do Rio de Janeiro. Procientista. Docente do Mestrado em Educação: processos formativos e desigualdades sociais. Vice-líder do Grupo de Pesquisa Vozes da Educação: História(s), memória(s) e formação de professores. E-mail: mairce@hotmail.com

Mestra do programa de Mestrado em Educação: processos formativos e desigualdades sociais (FFP/UERJ). Especialista em Educação Ambiental pela (UFF) e em Gestão Educacional pela (FFP/UERJ). Professora da Secretaria de Estado de Educaçáo do Rio de Janeiro (SEEDUC). nadia. rodrigues1@gmail.com 
Os ninguéns: os nenhuns, correndo soltos, morrendo a vida, fodidos e mal pagos:

Que não são, embora sejam.

Que não falam idiomas, falam dialetos. Que não praticam religiôes, praticam superstiçôes.

Que não fazem arte, fazem artesanato.

Que não são seres humanos, são recursos humanos.

Que não têm cultura, têm folclore.

Que não têm cara, têm braços.

Que não têm nome, têm número.

Que não aparecem na história universal,

aparecem nas páginas policiais da imprensa local.

Os ninguéns, que custam menos

do que a bala que os mata.

(Eduardo Galeano)

Escolhemos o poema “Os Ninguéns", de Eduardo Galeano, para iniciar nossa reflexão sobre diálogos interculturais escola/comunidade e suas repercussóes no processo de alfabetização das crianças das classes populares, bebendo na fonte da poesia. Em interlocução com Galeano, levantamos como hipótese que os seus "ninguéns, mais baratos que as balas que os matam", fazem parte de uma parcela expressiva da populaçáo brasileira que vive os processos de interdição ao direito a uma escolarização pública de qualidade que, dentre outros aspectos, garanta o acesso à leitura e à escrita.

Tal percepção teve como base pesquisa desenvolvida no Mestrado em Educação da Faculdade de Formação de Professores da Universidade do Estado do Rio de Janeiro em uma escola pública, localizada na área rural do município de Cachoeiras de Macacu, no interior do estado do Rio de Janeiro, que atende a uma comunidade tradicional formada há pelo menos 200 anos.

A pesquisa trouxe para nós várias questóes que nos ajudaram a pensar sobre o processo de interdição à leitura e à escrita que sofrem as crianças das classes populares. Dentre elas, o que era identificado como uma dificuldade de comunicação entre professoras e crianças nos chamou a atenção. As reflexóes sobre tal dificuldade nos possibilitaram colocar no centro da discussão a perspectiva monocultural que prevalece em nossas escolas e que, ao hierarquizar, rotular e estereotipar diferenças culturais, sobrepóe novos empecilhos ao processo de alfabetização.

Dados retirados do PNAD $2008^{1}$ nos ajudam a desenhar rostos para os ninguéns, tão belamente denunciados por Galeano. Assim, a mensuração da escolaridade da população jovem de 18 a 24 anos de idade com 11 anos de estudo é um índice apontado como essencial tanto para a avaliação do sistema educacional de um país quanto para medir a capacidade de uma sociedade para combater a pobreza e melhorar a coesão social. Tal índice, no Brasil, mesmo tendo dobrado em um período de dez anos, passando de 18,1\% em 1998 para 36,8\% em 2008, ainda é extremamente baixo. Isto significa que, apesar de um grande esforço, muito menos do que $50 \%$ de nossos jovens de 18 a 24 anos haviam concluído, há seis anos, o Ensino Fundamental.

O mais grave, porém, são as informaçōes que confirmam o caráter discriminador e racista que ainda prevalece no sistema educacional. O documento "Uma análise das condições de vida da população brasileira de 2009 "2 aponta que, ao se considerar cor ou raça como parâmetro, o percentual de $40,7 \%$ de pessoas brancas com 18 a 24 anos de idade, com 11 anos de estudos, era superior ao de $33,3 \%$, referente às pessoas de cor preta e parda. As desigualdades regionais, também, são marcantes neste indicador. Assim, enquanto na Região Sudeste a proporção era de $43,8 \%$ da totalidade dos jovens da referida faixa etária que possuía uma escolaridade de 11 anos, na Regiāo Nordeste este percentual caía para 29,2\% (p. 39). Se os índices da Região Sudeste por si só já nos deixam bastante preocupadas, o que dizer, então, dos percentuais da Região Nordeste?

As pesquisas acadêmicas, historicamente, têm se debruçado em busca de explicaçóes para a permanência do quadro ainda incipiente apresentado pelos números do nosso sistema educacional, especialmente quando falamos no domínio da leitura e da escrita. Muitas teorias e hipóteses têm sido levantadas ao longo das 
últimas décadas. Não temos a pretensão de inventariar aqui o acúmulo de conhecimentos, reflexóes, proposições elaboradas para responder a tais questóes. Conhecimentos que, atravessando os campos da pedagogia, da sociologia, da psicologia, da medicina, da economia, da política, dentre outros, muitas vezes sob o viés da cientificidade, contribuem para ocultar a desigualdade social que grita a partir de estatísticas, como as apresentadas anteriormente, e deslocam para o caráter público do ensino ou para as professoras, as crianças e suas famílias a responsabilidade pela (má) qualidade da escola.

O alerta de Garcia (1988) continua atual: $a$ alfabetizaçâa é responsabilidade de todos:

Discutir alfabetização é discutir o projeto político que se pretende para esse país, não apenas pelas consequências sociais do analfabetismo, mas também porque o modo como se direciona a prática pedagógica traz uma determinada concepção de mundo e de homem (p. 25).

No entrecruzamento da questão da alfabetização com as concepções de mundo, de homem e de sociedade que permeiam as práticas alfabetizadoras na escola é que encaminhamos nossa discussão no presente artigo.

Um breve retorno a algumas das explicaçóes sobre o que é identificado como "dificuldades de aprendizagem" das crianças das classes populares no processo de alfabetização, que tiveram força entre nós em décadas anteriores, aponta que as supostas razóes para as dificuldades das crianças estavam relacionadas ao contexto sociocultural da criança, em uma associação linear entre pobreza material e pobreza simbólica e cultural.

Contudo, embora tais argumentações ainda hoje encontrem acolhida tanto na sociedade quanto no cotidiano escolar, estudos sociológicos e antropológicos não deixam dúvidas que negar a ausência de cultura em qualquer grupo social também significa negar a existência do próprio grupo.
Todo sistema cultural tem a sua própria lógica e não passa de um ato primário de etnocentrismo tentar transferir a lógica de um sistema para outro. Infelizmente, a tendência mais comum é de considerar lógico apenas o próprio sistema e atribuir aos demais um alto grau de irracionalismo (LARAIA, 2001, p. 42).

Como decorrência do reconhecimento de que não existem sistemas culturais lógicos e pré-lógicos, como se cogitou nos primórdios da antropologia, o conceito de diversidade cultural ganha força. Existe uma diversidade de culturas. As culturas são diferentes umas das outras, qualquer hierarquização entre elas seria cientificamente incorreto. Entretanto, como a realidade também é atravessada pelos aspectos ideológicos e políticos, na prática, os padrôes culturais das classes populares acabam sendo identificados como subculturas em relaçáo a uma cultura das classes dominantes, reconhecida como a legítima.

É esta lógica que é denunciada no texto de Galeano. Sem a garantia da escolaridade garantida por lei, apartados de bens materiais e do acesso a bens culturais, quantas crianças e jovens brasileiros das classes populares estão refletidas no espelho dos ninguéns: "não são, embora sejam, não falam idiomas, falam dialetos, náo praticam religióes, praticam superstiçóes, não fazem arte, fazem artesanato, não têm cultura, têm folclore".

Como afirmava Soares (1988) há três décadas, silenciosamente, as práticas escolares vão fortalecendo e justificando a discriminação, cuja origem é social; a diferença vai se transformando em deficiência, o diferente vai sendo estigmatizado como carente. $\mathrm{O}$ uso da língua pelas crianças das classes populares na escola é um dos indicativos da diferença que se transforma em deficiência à medida que, ao utilizar-se de uma variante linguística diferente da reconhecida e legitimada pela escola, a criança, que já sofre um processo de marginalização social fora desse ambiente, continua 
a ser vista como carente, apenas por náo fazer uso da variante valorizada pela escola, e acaba fracassando (ARAUJO, 2003).

Para questionar o pressuposto de que a criança fracassa na escola por carência linguística, Goodman (1982) aponta que é muito difícil uma criança aprender a ler em um dialeto diferente do seu. Por meio da língua, a criança constrói, junto com a sua comunidade, uma visão de mundo, valores e percepçóes. Considerando que nos meios populares a linguagem oral é especialmente importante como instrumento de comunicação e transmissão da herança cultural, o não reconhecimento da sua variante linguística, do seu falar, implica também um silenciamento e uma negação de seus valores, lógicas, conhecimentos, visóes de mundo.

Essa perspectiva ajuda a reconhecer o triplo processo de interdição que as crianças das classes populares sofrem na escola: de um lado, não se legitima, nem se reconhece como conhecimento o acervo cultural que elas trazem consigo, a partir da tradição oral; de outro, não se facilita a apropriação de novos códigos culturais, não tão familiares para ela, produzidos a partir da língua escrita e, finalmente, ela mesma não se sente capaz de aprender (ARAUJO, 2003).

\section{Diálogos interculturais na} ESCOLA E AMBIENTES ALFABETIZADORES: OUTROS OLHARES PARA O PROCESSO DE ALFABETIZAÇÃO DAS CRIANÇAS DAS CLASSES POPULARES

Compromissadas em contribuir com o rompimento do processo de interdição à leitura e à escrita, discutido anteriormente, temos buscado em Freire (1992) uma concepção de alfabetização que, reconhecendo o sujeito que aprende como portador de lógicas, visóes de mundo e de sociedade, tome como referência que aprender a ler e escrever é, antes de mais nada, aprender a ler o mundo, compreender o contexto, localizar-se no espaço social mais amplo.

Nesse sentido, o conceito e as práticas de alfabetização se ampliam, transcendendo o seu conteúdo etimológico de lidar com as letras e palavras instrumentalmente, passando a traduzir as relaçóes das crianças com o entorno, com a cidade, com o mundo, mediadas pela semiótica urbana e pelo meio técnico-científico-informacional (ARAÚJO; PEREZ; TAVARES, 2008). Assim, a concepção de alfabetização que nos inspira reconhece, essencialmente, os/as educandos/as como sujeitos produtores de cultura.

Contudo, é importante ressaltar que ainda predomina, nos cursos de formação de professores, como herança do nosso processo de colonização, uma concepção de cultura dicotomizante que hierarquiza as práticas culturais (GARCIA, 2003, 2006, 2008; MOREIRA, 2003; SILVA, 1999). Em nosso cotidiano, tanto da escola quanto da própria sociedade, permanecem vivas e pulsantes as marcas de uma cultura dominante (europeia, branca, masculina, cristá...) que se autonomeava representante do avanço (científico, civilizatório, social) e se impunha sobre culturas dominadas (indígenas, africanas) identificadas como representantes do "atraso e da ignorância".

É a visão etnocêntrica ora presente nas cartilhas de alfabetização que elege um modelo de família, por exemplo, pai, mãe, filho, filha, como se esse fosse o protótipo da "família ideal", ora presente nos murais das paredes escolares, repletos de modelos louras, magras e de cabelos lisos, como espelhos referenciais para crianças negras, mestiças, indígenas, das escolas rurais...

Santos (2000) nos dá uma dimensão do desafio que representa ver a escola como um espaço intercultural ao discutir o processo de silenciamento a que as culturas "dominadas" foram submetidas. O silêncio que resultou do epistemicídio, ou seja, da destruição das muitas formas de saber dos povos que foram objetos do colonialismo 
ocidental, é um dos elementos dificultadores de um diálogo intercultural. Sob o rótulo da ignorância e do atraso, culturas, saberes, lógicas, formas de pensar e ver a realidade dos povos conquistados foram sendo silenciadas, "em nome de uma razâo que de fato era uma razão imposta de uma 'raça', de um sexo, de uma classe social” (SANTOS, 2000, p. 30).

$\mathrm{Na}$ produção de uma forma de pensar e conhecer hegemônica e colonizadora, o silenciamento foi uma peça-chave na construção de um patrimônio cultural universal. A ideia de transmissão de uma cultura universal e patrimonialista de uma geração para a outra - papel da escola atribuído pelas teorias liberais de educação - pressupóe uma sociedade em que todos os bens culturais contribuem para formar um capital cultural único, de propriedade coletiva, a que todos tenham acesso.

A perspectiva freireana inverte essa lógica ao tomar como ponto de partida no processo de alfabetizaçáo o reconhecimento de todo sujeito como produtor de cultura, favorecendo uma perspectiva intercultural:

[...] não podemos deixar de lado, desprezado como algo imprestável, o que educandos, sejam crianças chegando à escola ou jovens e adultos a centros de educação popular, trazem consigo de compreensão do mundo, nas mais variadas dimensôes de sua prática na prática social de que fazem parte. Sua fala, sua forma de contar, de calcular, seus saberes em torno do chamado outro mundo, sua religiosidade, seus saberes em torno da saúde, do corpo, da sexualidade, da vida, da morte, da força dos santos, dos conjuros (FREIRE, 1992, p. 8586).

Em artigo publicado em 1993, intitulado "Alfabetização tem conteúdos?", tendo como referência experiências vividas com professoras alfabetizadoras e inspirada pelos princípios freireanos, defendemos a importância de refletirmos sobre o processo de alfabetização a partir de conteúdos pedagógicos:

\begin{abstract}
Ao questionar professoras alfabetizadoras sobre o conteúdo trabalhado tanto na pré-escola quanto nas classes de alfabetização, tenho encontrado uma reação de surpresa diante de uma questáo, cuja resposta parece óbvia: o conteúdo da alfabetização é ensinar a ler e a escrever. Ler e escrever, porém, incidem sobre algum objeto contextualizado socialmente - ler o quê, escrever o quê? (ARAUJO, 1993, p. 83).
\end{abstract}

A partir de perguntas simples, tais como "ler o quê, escrever o quê?", temos buscado tornar complexas concepçóes de alfabetização, centradas na aquisição do código escrito e na análise da estrutura da língua, em busca de construir uma relação mais orgânica e significativa entre a criança e a linguagem escrita, de forma que aprender a ler e a escrever signifique se apropriar de ferramentas que lhe possibilitem pensar, imaginar, recriar o seu contexto existencial, na perspectiva apontada por Freire (1989), embora nosso esforço para contribuir com a construção de outras práticas alfabetizadoras seja desafiado cotidianamente.

Lembranças resgatadas do processo de alfabetizaçáo de uma das autoras do presente artigo confirmam isso. O relato a seguir é parte do memorial de formação produzido no decorrer da investigação que será apresentada posteriormente.

Em 1972 ingressei na escola no antigo CA (Curso de Alfabetização) sabendo ler e escrever. Fui alfabetizada em casa por minha mãe, que possuía apenas a quarta série do antigo curso primário. Náo sei que tipo de "metodologia" minha máe utilizou e, quando revivo esta memória, reflito sobre os problemas encontrados pelas crianças que ingressam nos ambientes escolares com gradientes muito diferentes de experiências. Lembro-me como era extremamente irritante passar horas do dia fazendo ondinhas nos meus cadernos quando já me apropriava (lia, escrevia e entendia) de uma quantidade razoável de palavras de meu cotidiano. Assim foram 3 cartilhas utilizadas por mim no meu primeiro ano de vida escolar e, entre "Vavá viu a uva, Vovô vê a ave, a ave voa", havia uma lição que até hoje me causa estranheza: era a lição do cê-cedilha, que era mais ou menos assim: $O$ cavalo cai no poço O moço vê o cavalo. O moço joga o laço no pescoço do cavalo. Embora conhecesse todas as palavras e letras, nunca entendi como o moço

Instrumento: R. Est. Pesq. Educ., Juiz de Fora, v. 19, n. 1, jan./jun. 2017 
jogava o laço no pescoço do cavalo dentro do poço. Ao lado das frases vinham desenhadas as figuras do poço, do moço, do laço e do cavalo e, ao meu olhar, aquele cavalo enorme jamais cairia dentro daquele poço pequeno, e, se caísse, jamais poderia ser laçado e retirado de lá. Como li perfeitamente a lição, mesmo não compreendendo o sentido, recebi "parabéns" e segui para a próxima família silábica da cartilha (RODRIGUES, 2013, p. 32).

O relato de Rodrigues, além de nos mostrar uma alfabetização reduzida ao processo de decifração de um código, igualmente nos mostra como esse processo gera estranhamento nas próprias crianças: "nunca entendi como o moço jogava o laço no pescoço do cavalo dentro do poço" (RODRIGUES, 2015, p. 32). Assim como tantas outras crianças, a autora vai em frente e, mesmo sem entender o significado do texto, aprende a ler; porém, quantas outras crianças não vão se perdendo pelo caminho?

Pensar o processo alfabetizador a partir de conteúdos que possam favorecer uma compreensão mais ampla de contexto social, incorporando na sala de aula os saberes das crianças sobre si, sobre o mundo, sobre a natureza e sobre a sociedade, favorece a emergência de outras práticas de leitura e escrita na escola.

É nessa perspectiva que propusemos uma ressignificação da concepção de ambientes alfabetizadores na escola, buscando contemplar práticas alfabetizadoras que potencializem crianças e jovens a dizer de si, do grupo social e da sociedade da qual fazem parte.

Acreditamos que o fortalecimento de ambientes alfabetizadores favoráveis às crianças das classes populares, valendo-se de uma perspectiva intercultural, precisa acolher e dialogar com as histórias, experiências, valores, universo cultural, leituras de mundo dessas crianças. A tarefa da escola dever ser ajudá-las a traduzir/ ampliar/aprofundar essas leituras de mundo, também por meio da língua escrita.

As reflexóes sobre alfabetização das crianças das classes populares que fomos acumulando em nossas trajetórias, em diálogo com Freire (1978, 1989, 1992), Garcia (1988, 2003, 2006,2008), Santos (2000), dentre outros autores e autoras, ajudaram-nos a elaborar uma questão: como fortalecer nas escolas ambientes alfabetizadores que contribuam para alfabetizar as crianças das classes populares sem lhes impor valores e formas de ser, fazer, pensar, dizer, que silenciem e apaguem suas próprias formas de ver e estar no mundo (ARAUJO, 2003a)?

\section{A PESQUisa E O CAMINHO PERCORRIDO ENTRE CÉUS E SERRAS...}

A investigação tem como lócus a Escola Estadual Bom Jardim, que se localiza na área rural do município de Cachoeiras de $\mathrm{Macacu}^{3}$, na região noroeste do estado do Rio de Janeiro, tendo como colaboradoras as duas professoras que lá atuam. Tal escola é organizada sob o regime de classes multisseriadas e atende ao primeiro segmento do ensino fundamental.

A motivaçáo para o desenvolvimento do trabalho foi a constatação do alto índice de fracasso das crianças daquela escola no processo de alfabetizaçáo. Os dados da Secretaria Municipal de Educação de Cachoeiras de Macacu de 2009 apontavam que 80\% dessas crianças não conseguiram se alfabetizar. Esse dado constituía uma exceção em relação às demais escolas localizadas na área rural do município.

Os primeiros contatos com a escola, ainda na fase exploratória da pesquisa, apontaram para uma dificuldade de comunicação entre professoras e crianças, em função de um comportamento das crianças identificado pelas professoras como apático e alheio às aulas. Buscando respostas para esta aparente apatia, ampliamos nosso olhar para o contexto no qual as crianças estavam inseridas. Analisando o cenário relativo à idade/série/moradia dos alunos, observamos que a maioria dos/das estudantes que se encontravam 
em situação de defasagem idade/série, por conta de suas "dificuldades" no processo de alfabetização, fazia parte da comunidade conhecida em Cachoeiras de Macacu por "Comunidade dos Hervanos". Praticamente todos os alunos da escola tinham algum grau de parentesco com a comunidade, mesmo que já não estivessem morando nos lugares de origem.

Algumas informações sobre a "Comunidade dos Hervanos" nos permitiram levantar que se trata de uma comunidade tradicional, que se encontra na localidade há pelo menos 200 anos, tem sua origem em etnias africanas e indígenas e se constituiu através de laços familiares. As famílias se fixaram em pelo menos duas localidades razoavelmente próximas à escola, que são chamadas de "Araçazeiro" e "Serra Suja". Vivem praticamente isolados em núcleos familiares e casam-se entre si.

Nós nos debruçamos sobre as entrevistas realizadas com as professoras, com objetivo de compreender melhor os atravessamentos que foram se colocando na relação ensino-aprendizagem entre professoras e crianças, dificultando a apropriação da leitura e da escrita.

Nesse sentido, nasceu a questão de pesquisa que nos desafiou a pensar até que ponto a perspectiva monocultural, característica da sociedade contemporânea, fazendo-se presente na escola ao rotular e estereotipar diferenças culturais, sobrepóe novos empecilhos ao processo de alfabetização.

No presente trabalho, abordamos duas questóes que foram demandadas a partir do diálogo com as entrevistas: o reconhecimento da criança como o "outro", tendo Larrosa (2006) como interlocutor, e uma reflexão sobre diferença e diversidade cultural, para a qual buscamos apoio em Gusmão (2012) e Freire (1978).

\section{A CRIANÇA É o "OUtro"}

Uma primeira questão que nos mobilizou ao buscar entender os desencontros de crianças-professoras, no contexto daquela escola, parecia traduzido para nós pela fala de Larrosa: "as crianças, esses seres selvagens que não entendem nossa língua”. Mesmo que nossas ciências já tenham formulado um acúmulo expressivo de teorias e práticas sobre as crianças, as dúvidas permanecem: as crianças nos entendem? Falamos a mesma língua? O sentimento de estranhamento da professora diante do grupo de crianças oriundas da Comunidade dos Hervanos, de certa forma, também revelava essa preocupação: "eles têm um dialeto diferente, as pessoas podem até dizer que não, mas só quem trabalha aqui sabe..." Para a professora, as crianças falavam outra língua, ela não as entendia.

Por outro lado, podíamos ler, a partir da angústia da professora, diante de seu não entendimento do dialeto das crianças, o alerta de Goodman (1982) sobre o desafio que representa para a criança aprender a ler em um dialeto diferente do seu. Aprender a ler e a escrever em outra língua significa penetrar em uma outra visão de mundo, de valores e de percepçóes. Junto com o não reconhecimento da sua variante linguística, vinha também o silenciamento e a negaçâo de seus valores, lógicas, visóes de mundo. Intuitivamente, a professora percebia isso, mas não sabia o que fazer.

Mesmo assim, buscava um caminho: "na verdade, eu tô ainda tentando me estabilizar, criar estratégia de obter uma relação com eles, porque a comunidade é diferente" (depoimento da Professora Dina). 
Construir estratégias de aproximação como resposta à inquietação provocada pela insegurança diante desse "outro" que, "ao náo falar" ou "ao falar outro dialeto" provoca inquietaçóes, questiona saberes e práticas já estabelecidas, abre a possibilidade para que a professora possa se colocar no lugar de quem pode e tem o que aprender com a criança, sobre os seus próprios modos de ver e pensar o mundo. Em outras palavras, tal perspectiva favorece o reconhecimento da criança como grupo social de sujeitos ativos.

\section{DiversidAde CULTURAL - DIFERENÇA CULTURAL}

Outra pista que encontramos para pensar o estranhamento das professoras diante das formas de expressão das crianças da Comunidade dos Hervanos nos remeteu à reflexão sobre diversidade e diferença cultural.

[...] eu falo que eles têm um dialeto diferente, as pessoas podem até dizer que não, mas só quem trabalha aqui sabe... (depoimento da Professora Cássia).

[...] quando vim para cá, encontrei uma escola com crianças totalmente introvertidas, que se escondiam no mato quando me viam, desviavam o rosto, sabe, uma outra realidade, mas foi um quadro assim meio que desesperador (depoimento Professora Dina).

As narrativas das professoras sobre os primeiros encontros na escola com as crianças reforçavam a ideia da "diferença": dialeto diferente, crianças introvertidas, hábitos estranhos, outra realidade...

O que é ser diferente em uma sociedade de iguais? A pergunta que tem sido colocada por pesquisadores e pesquisadoras, tais como Correa (1992), Gusmão (2006) e Jesus (2013), serviu-nos de guia para a reflexão.

A sociedade brasileira, como Gusmão (2012) nos ajuda a pensar, mesmo se autorreconhecendo como moderna, democrática e plural, constituída por múltiplas etnias e culturas, tem na ideia de progresso e de futuro sua grande meta, delegando à educação e à escola o papel de formar o cidadão para essa sociedade.

Para atingir tal objetivo, é preciso "apagar as diferenças" oriundas da multiplicidade das etnias e culturas que nos constituíram historicamente, negando o passado e as experiências dos sujeitos, sejam esses sujeitos pensados enquanto indivíduos, sejam pensados enquanto grupos étnicos ou classes sociais. Produzir um sistema educacional que busca a homogeneização demanda a exclusão do "diferente", do "outro". Rotular e estereotipar diferenças culturais é parte do processo de homogeneização funcional a uma sociedade capitalista.

Os termos diversidades culturais e diferença não são sinônimos, embora frequentemente sejam tratados como se fossem. São conceitos que por vezes se tangenciam e se complementam. Tal entendimento requer uma leitura mais aprofundada das relaçóes existentes entre os sujeitos. Dialogando com Gusmão (2012), vamos entender que a diversidade cultural é configurada através dos confrontos das diferenças entre sociedades, só há sentido em falar em "diversidade cultural a partir deste confronto, pois exige de cada um de nós a promoção da comunicação de experiências socioculturais" (idem, p. 158) que se faz em um determinado período histórico. A linha tênue entre diversidade e diferença está em entender tais diferenças e talvez a origem das mesmas.

$\mathrm{Na}$ medida em que definimos que "diferença é algo que se produz socialmente via um sentido simbólico e um sentido histórico, localizado e definido" (p. 149), cabe indagarmos: quem é diferente? Por que é diferente? Diferente em quê? Como?

O entendimento sobre a relaçáo diversidade cultural e diferenças culturais só é possível a partir de uma análise profunda sobre as relações sociais nas instituições e da visão ampliada do "outro" e do "eu", já que as diferenças só podem ser estabelecidas através 
da preconcepção de um eu, de um outro e de uma determinada sociedade. O outro é diferente porque e quando eu sou a referência.

Nesse sentido, podemos pensar a escola como um lugar que, ao acolher sujeitos portadores de diferentes experiências socioculturais, é também um lugar da diversidade por excelência, onde, contudo, inúmeras vezes as diferenças acabam sendo hierarquizadas e transformadas em fatores de exclusão e discriminação.

Sendo a escola um espaço, por excelência, da diversidade, algumas questóes se colocam como potencializadoras para um projeto de escola comprometido com uma sociedade mais igualitária: como construir um diálogo potente entre diferentes saberes produzidos pelos sujeitos a partir de diferentes experiências culturais? Como construir pontes que conectem experiências de grupos sociais diferentes sem hierarquizá-las?

Em outras palavras, trata-se de articular um diálogo que pense a escola como uma comunidade intercultural, não no sentido de minimizar as diferenças ou as diversidades, mas na direção de promover o conhecimento mútuo através das trocas de saberes e que possam destituir a lógica hegemônica de hierarquização cultural.

\section{A ESCOLA COMO ESPAÇO INTERCULTURAL: POSSIBILIDADES E IMPOSSIBILIDADES}

Um fio condutor de nossas reflexóes sobre as dificuldades encontradas por professoras e crianças da Comunidade dos Hervanos no processo de alfabetização, portanto, remeteu-nos à discussão sobre a questão cultural. Estamos em uma comunidade onde a diversidade cultural se explicita de uma forma gritante e as diferenças se transformam em problemas que desafiam não só as professoras, como também o próprio sistema educacional.
O relato da professora assinala suas dificuldades de diálogo com as crianças. Essa "dificuldade de comunicação" não poderia estar implicando diretamente no processo de alfabetização? Sem diálogo, como dizia Freire (1989), a possibilidade da articulação leitura do mundo e leitura da palavra se esvazia.

\begin{abstract}
Pra se ter uma ideia, quando eu vim para cá, os alunos não falavam comigo, eles ficavam naquele cantinho ali, falando entre eles, e eu não entendia o que eles estavam falando... Quando eles não querem que você saiba o que eles estão falando, eles ficam no caminho falando entre eles, eu chegava perto e eles saíam... Tem muitos aqui "de baixo" que não são da terra, mas são todos parentes e "a mente funciona muito parecido e a dificuldade de aprendizagem é grande, lá eles tem a dificuldade social porque náo tem luz nem saneamento básico, mas se você pensar em raciocínio são iguais (depoimento da Professora Cássia).
\end{abstract}

Atravessando e possivelmente dificultando o processo ensino-aprendizagem, o relato da professora nos permite reconhecer a escola como espaço da diversidade cultural - traduzido nas expressóes "eles ficam no caminho falando entre eles". Mais que isso, possibilita-nos ver também como a diferença vai sendo hierarquizada e colocada no lugar da subalternidade - "os de baixo, a mente funciona muito parecido e a dificuldade de aprendizagem é grande".

O distanciamento cultural entre professora e crianças parece ser um empecilho para o diálogo entre esses atores, pois, na medida em que existe uma fragilidade no compartilhamento dos sentidos culturais, a formação de conceitos, que estão na base do processo ensino-aprendizagem, fica comprometida.

Bakhtin (1988) nos lembra que:

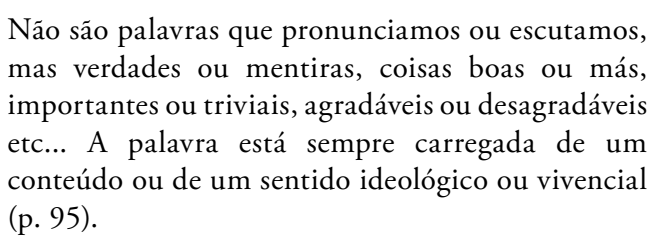

Se o que dá a significação às palavras, ou seja, o que determina o conteúdo das palavras, que é sempre 
ideológico, é o contexto sociocultural, uma condição para que haja um compartilhamento desses conteúdos na escola, como na sociedade, é que tal contexto cultural seja reconhecido por todos/as os/as envolvidos/as no processo ensino-aprendizagem: professores/as, alunos/ as, funcionários/as, comunidade.

O próximo relato nos mostra, porém, que um diálogo mais próximo escola-comunidade não depende apenas do reconhecimento dessa necessidade por parte da professora. Passa também por mudanças nas condições de trabalho dela:

Eu conheço alguns pais dos alunos que estudam
aqui, mas, como eu trabalho manhã aqui e tarde em
outra escola e quase não venho aqui na localidade,
eu não posso dizer que conheço a comunidade
em si, conheço alguns poucos pais que vêm aqui,
querendo saber alguma coisa do aluno, mas eles
quase não vêm aqui. Isto dificulta o trabalho e por
mais que a gente os chame, eles não vêm. Se no
centro urbano é difícil, imagina aqui. A relação é
muito distante e eles só vêm quando precisam de
algum documento, isto dificulta o trabalho do
professor, já que você está num território que náo
conhece (depoimento da Professora Cássia).

A professora entende que o conhecimento sobre o território no qual a escola se localiza seria muito importante para a construção de práticas pedagógicas mais potentes. Ela, dentro de suas possibilidades, chama os pais das crianças. Porém, as condições concretas inviabilizam seus movimentos. Duas matrículas, duas escolas, quem sabe uma casa para dar conta, filhos etc. Qual o tempo para estudo? Como estar disponível para um conhecimento mais amplo da comunidade, o que possibilitaria, quem sabe, um conhecimento mais amplo sobre sua própria prática pedagógica?

\section{Algumas conclusótes provisórias}

Estabelecer um diálogo intercultural na escola, que possibilite o compartilhamento de sentidos, implica reconhecer a todos e todas, professoras, professores, alunos, alunas, funcionários, funcionárias como sujeitos de culturas e de saberes. Tal diálogo pode contribuir para a revalorização das vozes, dos conhecimentos, das práticas sociais das populações historicamente excluídas da escola. Além disso, o diálogo intercultural pode contribuir igualmente para ampliar as possibilidades sociais de superação de uma lógica monocultural (Santos, 2000) que caracteriza a sociedade contemporânea e está profundamente arraigada na escola.

Os dados do Instituto de Pesquisas Econômicas Aplicadas (IPEA) apontam que temos hoje um percentual de $98 \%$ das crianças de 7 a 14 anos na escola. Crianças que trazem em sua bagagem referenciais culturais das mais diferentes origens étnicas, sociais, espaciais, religiosas, dentre outras, das quais as crianças da Comunidade dos Hervanos são apenas uma pequena amostra.

Se, por um lado, em um primeiro momento, tais diferenças tendem a ser anuladas, hierarquizadas, discriminadas, em função de uma lógica monocultural, ainda hegemônica, de outro, os confrontos produzidos pelas diferenças também podem, como decorrência, redimensionar as práticas pedagógicas lhe dando outros sentidos. Reconhecer a alteridade pode significar, assim, favorecer a emergência de relaçóes mais ecológicas entre diferentes saberes e formas de conhecer, como nos ensina Santos (2000).

Construir na escola possibilidades para que alunos e alunas sejam livres para expressarem suas culturas, seus valores, suas concepções de mundo exige reconhecer as diferenças, porém, deve-se ir além delas, como afirma Gusmão (2012), "para não reificá-las (como o faz o multiculturalismo) e impedir a emergência de uma realidade efetivamente intercultural. Esse é o desafio maior da escola, dos que educam e de todos nós" (p. 167).

Acreditamos que reside nessa perspectiva a fertilidade da investigação com as crianças e as 
professoras da Escola Estadual Municipalizada Bom Jardim, com as quais poderemos aprender a construir caminhos para romper com lógicas monoculturais, tão demarcadas em nossa sociedade, a partir de um diálogo intercultural, que favoreça um processo alfabetizador fundado no princípio freireano de que a leitura de mundo precede e acompanha a leitura da palavra.

\section{INTERCULTURAL DIALOGUES SCHOOL/ COMMUNITY AND ITS IMPACT ON CHILDREN'S LITERACY PROCESS OF THE WORKING CLASSES}

\section{Abstract}

This work is part of a research that was developed in the Master of Education FFP / UERJ in a public school located in a rural area of municipality Cachoeiras de Macacu, in the state of Rio de Janeiro that meets a traditional community formed for at least 200 years. In this work we bring to reflect on how far the monocultural perspective if does present at school, can label and stereotype cultural differences constituting an obstacle to popular education. Its main theoretical interlocutors Sarmento, Larrosa, Gusmão and Freire the from a research methodology of participatory nature, we seek to understand how does this process happens, and find clues to the production of an intercultural dialogue in school, that will contribute to voices valorization of, of the knowledge, of the social practices of populations historically excluded from school.

Keywords: Culture. Popular education. Intercultural dialogue.

\section{Diálogos interculturales escuela/ COMUNIDAD $Y$ SU IMPACTO EN EL PROCESO DE ALFABETIZACIÓN DE LOS NIÑOS DE LAS CLASES TRABAJADORAS}

\section{Resumen}

Este trabajo es un recorte de la investigación que fue desarrollada en la Maestría en Educación de la FFP/UERJ en una escuela pública, localizada en la zona rural del municipio de Cachoeiras de $\mathrm{Macacu}$, en el interior del estado de Río de Janeiro, que atiende a una comunidad tradicional formada hace por lo menos 200 ańos. En este trabajo traemos la reflexión sobre hasta que punto la perspectiva monocultural, haciéndose presente en la escuela, puede rotular y estereotipar diferencias culturales constituyendo un obstáculo a la educación popular. Teniendo como principales interlocutores teóricos a Sarmento, Larrosa, Gusmão y Freire a partir de una metodología de investigación de cuño participativo, buscamos comprender como se da ese proceso, bien como encontrar pistas para la producción de un diálogo intercultural en la escuela, que contribuya para la revalorización de las voces, de los conocimientos, de las practicas sociales de las poblaciones históricamente excluidas de la escuela.

Palabras clave: Cultura. Educación popular. Diálogo intercultural.

\section{Notas}

Disponível em: <http://www.ibge.gov.br/home/estatistica/popula cao/condicaodevida/indicadoresminimos/sinteseindicsociais 2009/indic_sociais2009.pdf>. Acesso em: 15 mar. 2015.

Idem.

O Município de Cachoeiras de Macacu tem hoje a maior parte de sua população localizada no centro urbano ( $1^{\circ}$ distrito), ficando, portanto, uma grande área de zona rural com baixa densidade demográfica. Justifica-se assim o fato de o município possuir 37 
escolas sob sua responsabilidade, sendo 13 com classes multisseriadas, e a Escola Estadual Municipalizada Bom Jardim é uma delas.

\section{REFERENCIAS}

AGENDA 21 CACHOEIRAS DE MACACU. Disponível em: <http://www.agenda21comperj.com.br/sites/localhost/ files/Cachoeiras.pdf>. Acesso em 8 jun. 2013.

ARAÚJO, M. S. O ambiente alfabetizador em questão: A luta pela qualidade de ensino nas escolas das classes populares. 2003.187 p. Tese (Doutorado em Educação), Universidade Federal do Rio de Janeiro, Rio de Janeiro, 2003.

Cenas do cotidiano de uma escola pública: olhando a escola pelo avesso. In: GARCIA, R. L. (Org.). Método: pesquisa com o cotidiano. Rio de Janeiro: DP\&A, 2003.

A sala de aula como entrelugar de culturas. In: GARCIA, R. (Org.). Novos olhares sobre alfabetização. São Paulo, Cortez, 1996.

Alfabetização tem conteúdos? In: GARCIA, R. L. (Org.). A formaçâa da professora alfabetizadora: reflexóes sobre a prática. São Paulo: Cortez Editora, 2003.

ARAÚJO, M.; PEREZ, C. L. V.; TAVARES, M. T. G. Caderno d@ professor@alfabetizador@ - Oficinas de alfabetização patrimonial e formação de professores. $H P$ comunicação Editora, Rio de Janeiro, 2008.

BAKHTIN, M. Marxismo e filosofia da linguagem. Sáo Paulo: Hucitec, 1988.

CORRÊA, M. A. M. De rótulos, carimbos e crianças nada especiais. Cadernos Cedes, São Paulo: Papirus. Número 28. 1992.

FREIRE, P. A educaçấo como prática da liberdade. SP: Paz e Terra, 1978.

Terra, 1989.

A importância do ato de ler. Rio de Janeiro: Paz e - A pedagogia da esperança. São Paulo: Paz e Terra, 1992.

GALEANO, E. Os ninguéns. In: GALEANO, E. O livro dos abraços. Porto Alegre: L\&PM, 2000.

GARCIA, R. L. Alfabetização, responsabilidade de todos. Revista Andes, v. 15, p. 25-35,1998.
GOODMAN, K. El processo de lectura: consideraciones através de las lenguas y del desarrollo. In: FERREIRO, E.; PALÁCIO, M. G. (Org.). Nuevas perspectivas sobre los processos de lectura e escritura. México: Siglo Veinteuno Ed. 1982/1984.

GUSMÃO, N. M. M. Diversidade cultural e a questão da diferença na educação. In: ARAUJO, M.; MORAIS, J. F. S. (Org.). Vozes da Educação. Formação de Professores, Narrativas, Políticas e Memórias. Rio de Janeiro: EDUERJ, 2012.

INSTITUTO BRASILEIRO DE GEOGRAFIA E ESTATÍSTICA. Sintese de indicadores sociais. Uma análise das condiçốes de vida da população brasileira. Estudos e Pesquisas. Informação demográfica e socioeconômica, n. 26, 2009.

LARAIA, R. B. Cultura: um conceito antropológico. Rio de Janeiro: Jorge Zahar Ed., 2001.

LARROSA, J. Pedagogia profana. Belo Horizonte: Autêntica Editora, 2006.

RODRIGUES, N. C. L. Diálogos interculturais e ambientes alfabetizadores na escola. Dissertação. 2015. 122f.. (Mestrado em Educação), Universidade Estadual do Rio de Janeiro, São Gonçalo, 2013..

SANTOS, B. S. A crítica da razáo indolente. Contra o desperdício da experiência. São Paulo: Cortez, 2000.

SILVA, T. T. Documentos de identidade. Uma introdução às teorias do currículo. Belo Horizonte: Autêntica, 1999. 154p.

SOARES, M. Linguagem e escola: uma perspectiva social. 6. ed. São Paulo: Ática, 1988.

ZACCUR, E. (Org.). Cotidiano e diferentes saberes. Rio de Janeiro: DP\&A, 2006.

- Alfabetização - reflexóes sobre saberes docentes e saberes discentes. São Paulo: Cortez Editora, 2008.

MOREIRA, A. F. B.; GARCIA, R. L. (Org.). Curriculo na contemporaneidade: incertezas e desafios São Paulo: Cortez Editora, 2003.

Enviado em 30 de setembro de 2015. Aprovado em 19 de dezembro de 2015. 